\title{
ALOKASI KEBUTUHAN ALAT BERAT PADA PROYEK PENINGKATAN JALAN BANDAREJO-KOTO TINGGI KABUPATEN PASAMAN BARAT
}

\author{
Ir. SURYA EKA PRIANA, MT \\ Program Studi Teknik Sipil, Fakultas Teknik Universitas Muhammadiyah Sumatera Barat \\ ekaprianasuryauj@gmail.com
}

\begin{abstract}
Abstrak: Alokasi, penjadwalan, dan pemilihan peralatan untuk setiap jenis pekerjaan sangat penting agar kemampuan operasinya bisa optimal dan saling menunjang terhadap peralatan lainnya. Mengingat bahwa alat berat sangat mahal dan konstribusinya cukup dominan pada proyek peningkatan jalan Bandarejo - Koto Tinggi Kabupaten Pasaman Barat, maka sangat diperlukan tindakan efisiensi dengan cara mendayagunakan sumber daya alat tersebut. Sehingga studi ini dimaksudkan untuk menganalisa alokasi alat berat dan penjadwalan. Pengamatan dilakukan dengan menghitung kapasitas produksi setiap alat berat, agar diperoleh nilai produktivitasnya dan alokasi kebutuhan alat berat yang diperlukan pada proyek yang ditinjau. Kemudian dengan menggunakan metode Line of Balance, maka dapat diplot pengalokasian alat berat untuk masing-masing jenis pekerjaan sesuai dengan kebutuhan alat yang lebih efisien, sehingga penggunaannya bisa dikontrol agar lebih efektif. Dari hasil perhitungan, diperoleh kebutuhan dump truck sebanyak 7 unit, motor grader 1 unit, wheel loader 2 unit, tandem roller 1 unit, vibrator roller 2 unit, water tank truck 2 unit, excavator 1 unit, pneumatic tire roller 1 unit, asphalt sprayer 1 unit, asphalt mixing plant 1 unit dan asphalt finisher 1 unit.
\end{abstract}

Kata kunci : Alokasi, Penjadwalan, dan Produktivitas

\begin{abstract}
Allocation, scheduling, and selection of equipment for each type of work is very important so that the ability to operate can be optimal and support each other for other equipment. Considering that heavy equipment is very expensive and its contribution is quite dominant in the Bandarejo - Koto Tinggi road improvement project in West Pasaman Regency, it is necessary to take efficiency measures by utilizing the tool's resources. So this study is intended to analyze heavy equipment allocation and scheduling. Observations were made by calculating the production capacity of each heavy equipment, in order to obtain the value of its productivity and the allocation of heavy equipment requirements needed for the project being reviewed. Then using the Line of Balance method, it can be plotted the allocation of heavy equipment for each type of work in accordance with the needs of a more efficient tool, so that its use can be controlled to be more effective. From the calculation results, we obtained 7 units of dump trucks, 1 unit of motor grader, 2 units of wheel loader, tandem roller 1 unit, 2 unit vibrator roller, 2 units of water tank truck, 1 unit excavator, pneumatic tire roller 1 unit, asphalt sprayer 1 unit, 1 unit asphalt mixing plant and 1 unit asphalt finisher.
\end{abstract}

Keywords: Allocation, Scheduling, and Productivity

\section{PENDAHULUAN}

Dalam pelaksanaan suatu proyek dipengaruhi oleh ketersediaan sumber daya yang akan diperlukan, termasuk pula dalam proyek pembangunan jalan raya. Ketersediaan tersebut dapat mempengaruhi efektifitas dan efisiensi pelaksanaan suatu proyek, baik dalam hal biaya maupun waktu pelaksanaan proyek. Salah satu sumber daya yang berperan penting adalah alat berat. Oleh karena konstribusi alat berat terhadap pelaksanaan proyek yang cukup penting serta biaya penggunaan alat berat yang relatif mahal, maka dibutuhkan suatu manajemen yang baik dalam mendayagunakan sumber daya alat berat ini.

Dalam menggunakan alat-alat berat untuk pembuatan konstruksi jalan perlu diperhatikan jenis konstruksi jalan, alat-alat berat yang dipakai, pengetahuan tentang kapasitas dan kemampuan alat berat agar memenuhi syarat penggunaan yaitu tidak menimbulkan pemborosan tenaga kerja, modal, 
produktivitas serta memenuhi kebutuhan keselamatan.

Alokasi, penjadwalan, dan pemilihan peralatan secara seksama pada setiap jenis pekerjaan sangat penting agar kemampuan operasinya bisa optimal.

\section{METODE PENELITIAN}

Gambaran Umum Proyek

Proyek kontruksi jalan nasional ini diidentifikasi dengan nama "Proyek peningkatan Jalan Bandarejo - Koto Tinggi Kabupaten Pasaman Barat". Proyek ini dilaksanakan oleh PT. Statika Mitra Sarana sebagai Kontraktor dengan panjang jalan \pm $2.500 \mathrm{~m}$.

Dana yang dibutuhkan untuk proyek peningkatan jalan ini adalah Rp. 2.500.000.000,00 dengan waktu pelaksanaan 23 Juli 2018 sampai dengan 19 Desember 2018.

Pekerjaan yang dilaksanakan pada proyek ini adalah :

1. Pekerjaan tanah yang meliputi pekerjaan galian, pekerjaan timbunan, dan penyiapan badan jalan.

2. Pekerjaan perkerasan berbutir meliputi: Lapis pondasi agregat kelas A dan Lapis pondasi agregat kelas B.

3. Pekerjaan perkerasan aspal meliputi: Lapis resap pengikat, Lapis perekat, Laston lapis aus (AC-WC), Laston lapis antara (AC-BC), dan Laston lapis pondasi (AC-Base).

Tabel 1. Jenis Alat Berat yang Digunakan

\begin{tabular}{|c|c|c|}
\hline No. & $\begin{array}{c}\text { Uraian } \\
\text { Pekerjaan }\end{array}$ & $\begin{array}{c}\text { Jenis Alat yang } \\
\text { Digunakan }\end{array}$ \\
\hline \multirow[t]{2}{*}{1.} & Galian & Excavator PC 200 \\
\hline & Biasa & $\begin{array}{l}\text { Dump Truck Hino } \\
\text { FM } 260\end{array}$ \\
\hline \multirow[t]{6}{*}{2.} & Timbunan & Excavator PC 200 \\
\hline & Biasa & Dump Truck Hino \\
\hline & & FM 260 \\
\hline & & Motor Grader GD \\
\hline & & $405 \mathrm{~A}$ \\
\hline & & Vibrator Roller 212D \\
\hline \multirow[t]{7}{*}{3.} & Timbunan & Wheel Loader \\
\hline & Pilihan & WA200 \\
\hline & & $\begin{array}{l}\text { Dump truck Hino } \\
\text { FM } 260\end{array}$ \\
\hline & & Motor Grader GD \\
\hline & & $405 \mathrm{~A}$ \\
\hline & & Tandem Roller \\
\hline & & BW141 \\
\hline
\end{tabular}

\begin{tabular}{|c|c|c|}
\hline & & $\begin{array}{l}\text { Water Tank Truck } \\
\text { Dyna }\end{array}$ \\
\hline 4. & $\begin{array}{l}\text { Penyiapan } \\
\text { Badan } \\
\text { Jalan }\end{array}$ & $\begin{array}{l}\text { Motor Grader GD } \\
\text { 405A } \\
\text { Water Tanker Truck } \\
\text { Dyna } \\
\text { Vibrator Roller 212D }\end{array}$ \\
\hline 5. & $\begin{array}{l}\text { Lapis } \\
\text { Pondasi }\end{array}$ & $\begin{array}{ll}\text { Wheel } & \text { Loader } \\
\text { WA200 } & \end{array}$ \\
\hline & $\begin{array}{l}\text { Agregat } \\
\text { (Kelas }\end{array}$ & $\begin{array}{l}\text { Dump Truck Hino } \\
\text { FM } 260\end{array}$ \\
\hline & A\&B) & $\begin{array}{l}\text { Motor grader GD } \\
405 \mathrm{~A} \\
\text { Vibrator Roller 212D } \\
\text { Water Tanker Truck } \\
\text { Dyna }\end{array}$ \\
\hline 6. & $\begin{array}{l}\text { Lapis } \\
\text { Resap } \\
\text { Pengikat }\end{array}$ & $\begin{array}{l}\text { Asphalt Sprayer } \\
\text { Kasprindo } \\
\text { Compressor Airman } \\
\text { Dump Truck Hino } \\
\text { FM 260 }\end{array}$ \\
\hline 7. & $\begin{array}{l}\text { Lapis } \\
\text { Perekat }\end{array}$ & $\begin{array}{l}\text { Asphalt Sprayer } \\
\text { Kasprindo } \\
\text { Compressor Airman } \\
\text { Dump Truck Hino } \\
\text { FM 260 }\end{array}$ \\
\hline 8. & $\begin{array}{l}\text { Asphalt } \\
\text { Concrete }\end{array}$ & $\begin{array}{l}\text { Wheel } \\
\text { WA200 } \\
\text { AMP Azp } 1000 \\
\text { Dump Truck Hino } \\
\text { FM 260 } \\
\text { Asphalt } \quad \text { Finisher } \\
\text { Nigata } \\
\text { Tandem } \\
\text { BW141 } \\
\begin{array}{l}\text { P. Tire Roller } \\
\text { Sakai }\end{array}\end{array}$ \\
\hline 9. & $\begin{array}{l}\text { Pembongka } \\
\text { ran } \\
\text { Pasangan } \\
\text { Batu }\end{array}$ & $\begin{array}{l}\text { Wheel Loader } \\
\text { WA200 } \\
\text { Dump Truck Hino } \\
\text { FM 260 } \\
\text { Compressor Airman }\end{array}$ \\
\hline 10. & $\begin{array}{l}\text { Pembongka } \\
\text { ran Beton }\end{array}$ & $\begin{array}{ll}\text { Wheel } & \text { Loader } \\
\text { WA200 } & \\
\text { Dump Truck } & \text { Hino } \\
\text { FM 260 } & \end{array}$ \\
\hline 11. & $\begin{array}{l}\text { Camp. } \\
\text { Aspal } \\
\text { Panas } \\
\text { Untuk } \\
\text { Pekerjaan } \\
\text { Minor }\end{array}$ & $\begin{array}{l}\text { Wheel } \quad \text { Loader } \\
\text { WA200 } \\
\text { AMP Azp } 1000 \\
\text { Dump Truck Hino } \\
\text { FM 260 } \\
\text { Asphalt } \\
\text { Nigata }\end{array}$ \\
\hline
\end{tabular}

Fakultas Teknik UMSB 


\section{Tandem Roller \\ BW141 \\ P. Tire Roller Sakai}

Lanjutan Tabel 1. Jenis Alat Berat yang Digunakan

\begin{tabular}{|c|c|c|}
\hline No. & $\begin{array}{c}\text { Uraian } \\
\text { Pekerjaan }\end{array}$ & $\begin{array}{c}\text { Jenis Alat yang } \\
\text { Digunakan }\end{array}$ \\
\hline \multirow[t]{3}{*}{12.} & Marka & Dump Truck Hino \\
\hline & Jalan & FM260 \\
\hline & $\begin{array}{l}\text { Thermoplas } \\
\text { tic }\end{array}$ & Compressor Airman \\
\hline 13. & $\begin{array}{l}\text { Kerb } \\
\text { Pracetak }\end{array}$ & $\begin{array}{l}\text { Dump Truck Hino } \\
\text { FM } 260\end{array}$ \\
\hline
\end{tabular}

Uraian dan Volume Pekerjaan

Besarnya volume pekerjaan pada proyek ini adalah berdasarkan data yang diperoleh dari kontraktor, yaitu sebagai berikut:

1. Pekerjaan tanah

Galian biasa

$5.449,54 \mathrm{~m}^{3}$

Timbunan Biasa

$: 351,85 \mathrm{~m}^{3}$

Timbunan Pilihan

: $671,00 \mathrm{~m}^{3}$

Penyiapan Badan Jalan $\quad: 10.000,00 \mathrm{~m}^{2}$

2. Pekerjaan perkerasan berbutir

Lapis pondasi agregat kelas A: $2.720,70 \mathrm{~m}^{3}$

Lapis pondasi agregat kelas B: $3.400,88 \mathrm{~m}^{3}$

3. Pekerjaan perkerasan aspal

Lapis peresap pengikat

$: 16.115,10 \mathrm{ltr}$

Lapis perekat

: $9.522,45 \mathrm{ltr}$

Asphalt Concrete

: 2.471,48 Ton

4. Pekerjaan Struktur

Pembongkaran Pas.Batu $\quad: \quad 150,00 \mathrm{~m}^{3}$

Pembongkaran Beton : $186,00 \mathrm{~m}^{3}$

5. Pengembalian Kondisi dan Pekerjaan Minor

Campuran Aspal Panas : $\quad 100,63 \mathrm{~m}^{3}$

Marka Jalan Thermoplastic : $1650,00 \mathrm{~m}^{3}$

Kerb Pracetak

: 20237,00 bh

\section{METODE PENJADWALAN DAN \\ ALOKASI \\ Produktivitas Alat}

Produktivitas atau kapasitas alat adalah besarnya keluaran (output) volume pekerjaan tertentu yang dihasilkan alat per-satuan waktu. Untuk memperkirakan produktivitas alat, diperlukan :

- kinerja alat yang diberikan oleh pabrik pembuat alat.

- Faktor efisiensi alat, operator, kondisi lapangan dan material.
Produktivitas alat dihitung berdasarkan volume per-siklus waktu dan jumlah siklus dalam satu jam.

$$
\mathrm{Q}=\mathrm{q} \times \mathrm{N} \times \mathrm{E}
$$

Dimana :

$\mathrm{Q}=$ produksi alat per $\mathrm{jam}\left(\mathrm{m}^{3} / \mathrm{jam}\right)$

$\mathrm{q}=$ produksi alat per siklus $\left(\mathrm{m}^{3} / \mathrm{siklus}\right)$

$\mathrm{E}=$ faktor efisiensi kerja total

$\mathrm{N}=$ jumlah siklus per jam, yaitu :

$$
\mathrm{N}=\frac{60}{W_{s}}
$$

Ws = waktu siklus ( menit)

Dengan demikian, produktivitas alat dapat dihitung dengan :

$$
\mathrm{Q}=\frac{\mathrm{q} \times 60 \times \mathrm{E}}{\mathrm{Ws}}
$$

Masing-masing alat berat mempunyai produktivitas spesifik sesuai dengan kapasitas produksinya :

1. Produksi Wheel Loader ( $\left.\mathrm{m}^{3} / \mathrm{jam}\right)$

$$
\mathrm{Q}=\frac{\mathrm{q} \times 60 \times \mathrm{E}}{\mathrm{Ws}}
$$

Dimana :

$$
\begin{aligned}
\mathrm{Q} & =\text { produksi alat per jam }\left(\mathrm{m}^{3} / \mathrm{jam}\right) \\
\mathrm{q} & =\text { produksi tiap siklus }\left(\mathrm{m}^{3}\right)=\mathrm{q}_{1} \times \mathrm{k} \\
\mathrm{q}_{1} & =\text { kapasitas bucket }\left(\mathrm{m}^{3}\right) \\
\mathrm{k} & =\text { faktor } \text { bucket } \\
\mathrm{E} & =\text { faktor efisiensi kerja total } \\
\mathrm{Ws} & =\text { waktu siklus }
\end{aligned}
$$

2. Produksi Excavator (m $3 / \mathrm{jam})$

$$
\mathrm{Q}=\frac{\mathrm{q} \times 60 \times \mathrm{E}}{\mathrm{Ws}}
$$

Dimana :

$$
\begin{aligned}
\mathrm{Q} & =\text { produksi alat per jam }\left(\mathrm{m}^{3} / \mathrm{jam}\right) \\
\mathrm{q} & =\text { kapasitas per siklus }\left(\mathrm{m}^{3}\right)=\mathrm{q}_{1} \times \mathrm{k} \\
\mathrm{q} 1 & =\text { kapasitas bucket }\left(\mathrm{m}^{3}\right) \\
\mathrm{k} & =\text { faktor bucket } \\
\mathrm{E} & =\text { faktor efisiensi kerja total } \\
\mathrm{Ws} & =\text { waktu siklus (menit) } \\
& =\mathrm{wg}+2(\mathrm{wp})+\mathrm{wb} \\
\mathrm{Wg} & =\text { waktu menggali (menit) } \\
\mathrm{Wp} & =\text { waktu putar (menit) } \\
\mathrm{Wb} & =\text { waktu buang/ muat (menit) }
\end{aligned}
$$

3. Produksi Dump Truck (m³/jam)

$$
\mathrm{P}=\frac{\mathrm{C} \times 60 \times \mathrm{E}}{W \mathrm{~W}}
$$


Dimana :

$\mathrm{P}=$ produksi alat per jam $\left(\mathrm{m}^{3} / \mathrm{jam}\right)$

$\mathrm{C}=$ kapasitas dump truck $\left(\mathrm{m}^{3}\right)$

$\mathrm{E}=$ faktor efisiensi kerja total

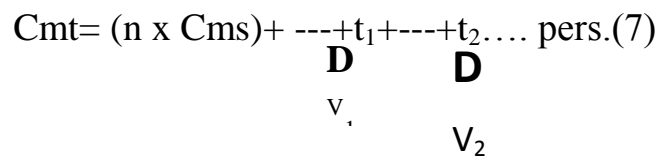

$\mathrm{n}=$ jumlah rit pengisian oleh pemuat

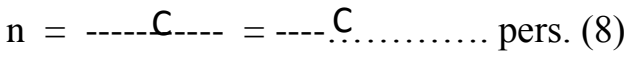

$\mathrm{q}_{1} \times \mathrm{k}$

$\mathrm{q}_{1}=$ kapasitas alat pemuat $\left(\mathrm{m}^{3}\right)$

Ws = waktu siklus alat pemuat (menit)

$\mathrm{D}=\operatorname{jarak}(\mathrm{m})$

$\mathrm{V}_{1}=$ kecepatan angkut rata-rata $(\mathrm{m} / \mathrm{menit})$

$\mathrm{V}_{2}=$ kecepatan kembali rata-rata $(\mathrm{m} / \mathrm{menit})$

$\mathrm{t}_{1}=$ waktu bongkar (menit)

$\mathrm{t}_{2}=$ waktu maneuver memuat kembali (menit)

4. Produksi Motor Grader ( $\left.\mathrm{m}^{3} / \mathrm{jam}\right)$

$$
\mathrm{Q}=\frac{\mathrm{V} \times(\text { Le-Lo }) \times \mathrm{H} \times \mathrm{E}}{\mathrm{Ws}} \ldots \text { pers. (9) }
$$

Dimana :

$\mathrm{Q}=$ produksi alat per jam $\left(\mathrm{m}^{3} / \mathrm{jam}\right)$

$\mathrm{V}=$ kecepatan kerja $(\mathrm{m} / \mathrm{jam})$

Le $=$ panjang efektif blade $(\mathrm{m})$

Lo $=$ lebar overlap $=0,3 \mathrm{~m}$

$\mathrm{E}=$ faktor efisiensi kerja total

$\mathrm{N}=$ jumlah trip

$\mathrm{Ws}=$ waktu siklus

5. Produksi Alat Pemadat $\left(\mathrm{m}^{3} / \mathrm{jam}\right)$

$$
\mathrm{Q}=\frac{\mathrm{W} \times \mathrm{V} \times \mathrm{H} \times \mathrm{E}}{\mathrm{N}} \ldots \ldots \ldots . . . \text { pers. (10) }
$$

Dimana :

$\mathrm{Q}=$ produksi alat per jam $\left(\mathrm{m}^{3} / \mathrm{jam}\right)$

$\mathrm{V}=$ kecepatan kerja $(\mathrm{km} / \mathrm{jam})$

$\mathrm{W}=$ lebar efektif compactor $(\mathrm{m})$

$\mathrm{H}=$ tebal lapisan pemadatan (antara $0,2-0,5 \mathrm{~m})$

$\mathrm{E}=$ faktor efisiensi kerja total

$\mathrm{N}=$ jumlah lintasan compactor

6. Produksi Water Tank Truck (m³/jam)

$$
\mathrm{Q}=\frac{\mathrm{C} \times \mathrm{N} \times \mathrm{E}}{\mathrm{Wc}}
$$

Dimana :

$\mathrm{Q}=$ produksi alat per jam $\left(\mathrm{m}^{3} / \mathrm{jam}\right)$

$\mathrm{C}=$ kapasitas bak/volume tangki $\left(\mathrm{m}^{3}\right)$

$\mathrm{n}=$ pengisian tangki perjam

$\mathrm{E}=$ faktor efisiensi kerja total

$\mathrm{Wc}=$ kebutuhan air $/ \mathrm{m}^{3}$ material padat

7. Produksi Asphalt Sprayer ( $\left.\mathrm{m}^{3} / \mathrm{jam}\right)$

$$
\mathrm{Q}=\frac{\mathrm{q} \times \mathrm{E}}{\mathrm{Ws}} \ldots \ldots \ldots \ldots \ldots \ldots \text { pers. (12) }
$$

Dimana :

$$
\begin{aligned}
\mathrm{Q} & =\text { produksi alat per jam }\left(\mathrm{m}^{3} / \mathrm{jam}\right) \\
\mathrm{q} & =\text { kapasitas tangki sprayer }\left(\mathrm{m}^{3}\right) \\
\mathrm{E} & =\text { faktor efisiensi kerja total } \\
\mathrm{Ws} & =\text { waktu siklus (menit) }
\end{aligned}
$$

8. Produksi Asphalt Finisher ( $\left.\mathrm{m}^{3} / \mathrm{jam}\right)$

$$
\mathrm{Q}=\mathrm{w} \times \mathrm{V} \times \mathrm{H} \times \mathrm{E}
$$

Dimana :

$\mathrm{Q}=$ produksi alat per jam $\left(\mathrm{m}^{3} / \mathrm{jam}\right)$

$\mathrm{w}=$ lebar penghamparan $(\mathrm{m})$

$\mathrm{V}=$ kecepatan kerja $(\mathrm{m} /$ menit $)$

$\mathrm{H}=$ tebal lapisan $(\mathrm{m})$

$\mathrm{E}=$ faktor efisiensi kerja total

9. Produksi Air Compressor ( $\left.\mathrm{m}^{3} / \mathrm{jam}\right)$

$$
\mathrm{Q}=\mathrm{q} \times \mathrm{Ap}
$$

Dimana :

$\mathrm{Q}=$ produksi alat per jam $\left(\mathrm{m}^{3} / \mathrm{jam}\right)$

$\mathrm{q}=$ kapasitas kerja alat

$\mathrm{Ap}=$ aspal perekat/pengikat $($ spec $)$

10. Kapasitas Produksi Asphalt Mixing Plant $\left(\mathrm{m}^{3} / \mathrm{jam}\right)$

$$
\mathrm{Q}=\frac{C x 60 x E}{W S}
$$

Dimana :

$$
\begin{aligned}
\mathrm{Q} & =\text { produksi alat per jam }\left(\mathrm{m}^{3} / \mathrm{jam}\right) \\
\mathrm{C} & =\text { kapasitas batch (ton) } \\
\mathrm{E} & =\text { faktor efisiensi kerja total } \\
\mathrm{Ws} & =\text { waktu siklus (menit) }
\end{aligned}
$$

Analisa Kebutuhan Peralatan

Kebutuhan peralatan dipengaruhi oleh:

1. Volume pekerjaan : $\mathrm{m}^{3}$

2. Durasi : hari

3. Jenis alat

4. Kapasitas produksi alat

5. Jam efektif alat : waktu yang dibutuhkan oleh alat untuk menghasilkan pekerjaan dalam jam

Durasi $=\frac{\text { Volume pekerjaan }\left(\mathrm{m}^{3}\right)}{\text { Kapasitas produksi alat }\left(\mathrm{m}^{3} / \mathrm{jam}\right)}$ 
Kebutuhan alat $=$ Volume pekerjaan $\left(\mathrm{m}^{3}\right)$

xDurasi

$$
\text { Kapasitas produksi alat }
$$

Perencanaan Schedule Peralatan

Line of Balance (LOB)

Line of balance adalah suatu diagram sederhana untuk menunjukkan lokasi (stasiun kerja) dan waktu di mana alat/tenaga kerja akan bekerja pada suatu item pekerjaan tertentu.

Tujuan dari metode line of balance adalah untuk menjamin bahwa sumber daya yang diperlukan baik dalam bentuk material ataupun tenaga kerja selalu tersedia dalam jumlah yang tepat pada waktu yang diperlukan sesuai dengan penjadwalan masing-masing aktivitas pekerjaan setiap unit. Sehingga tidak terjadi penumpukan material, peralatan atau tenaga kerja yang berlebihan ataupun kekurangan yang dapat mengakibatkan penundaan waktu kerja proyek.

Barchart (Bagan Balok)

Barchart adalah diagram alur pelaksanaan pekerjaan yang dibuat untuk menunjukkan waktu penyelesaian yang dibutuhkan. Hal-hal yang ditampilkan dalam barchart adalah jenis pekerjaan, durasi/waktu pelaksanaan pekerjaan maupun stasiun/lokasi pelaksanaan pekerjaan.

\section{HASIL DAN PEMBAHASAN}

Pekerjaan Galian Biasa

Berdasarkan rekapitulasi hasil pengamatan maka kapasitas produksi alat excavator dan dump truck pada pekerjaan ini dapat dihitung sebagai berikut:

1. Excavator $\mathrm{PC} 200$

$$
\begin{aligned}
\mathrm{Q} & =\frac{(q \times 60 \times E)}{W S} \\
& =\frac{0,72 \times 60 \times 0,81}{0,85} \\
& =41,17 \mathrm{~m}^{3} / \mathrm{jam} \text { (Loosened Condition) } \\
& =41,17 \times 0,80 \\
& =32,94 \mathrm{~m}^{3} / \mathrm{jam} \text { (Bank Condition) }
\end{aligned}
$$

2. Dump Truck Hino FM 260

$$
\begin{aligned}
\mathrm{P} & =\frac{(C x 60 x E)}{W S} \\
& =\frac{10,00 \times 60 \times 0,75}{26,25}
\end{aligned}
$$

$=17,14 \mathrm{~m}^{3} / \mathrm{jam}($ Loosened Condition $)$

$=17,14 \times 0,80$

$=13,71 \mathrm{~m}^{3} / \mathrm{jam}$ (Bank Condition)

Perhitungan Kebutuhan Alat Berat

Pekerjaan Galian Biasa

Kebutuhan peralatan untuk pekerjaan galian biasa:

Volume pekerjaan $\quad=5.449,54 \mathrm{~m}^{3}$

Jam kerja efektif per hari $\quad=7$ jam kerja

1 bulan

$=25$ hari kerja

Alat yang digunakan pada pekerjaan galian biasa:

1. Excavator PC200

Produksi per jam $=41,17 \mathrm{~m}^{3} / \mathrm{jam}$

$$
=288,19 \mathrm{~m}^{3} / \text { hari }
$$

Durasi $=$ Volume $/$ Kapasitas produksi

$$
\begin{aligned}
& =5.449,54 \mathrm{~m}^{3} / 41,17 \mathrm{~m}^{3} / \mathrm{jam} \\
& =132,37 \mathrm{jam} \\
& =18,91 \text { hari }
\end{aligned}
$$

Durasi pekerjaan untuk galian biasa berdasarkan perencanaan $=21$ hari

Sehingga diperoleh jumlah kebutuhan alat berat pada pekerjaan galian biasa adalah sebagai berikut:

$$
\begin{aligned}
& \text { Kebutuhan alat }=\frac{\text { Volume pekerjaan }}{\text { Kapasitas produksi } x \text { Durasi }} \\
&= \\
& \frac{5449,54 \mathrm{~m} 3}{288,19 \mathrm{~m} 3 / \text { hari } \times 21,00 \text { hari }} \\
&=0,90 \approx 1 \text { unit }
\end{aligned}
$$

2. Dump Truck Hino FM 260

Produksi per jam $=17,14 \mathrm{~m}^{3} / \mathrm{jam}$

$$
=119,98 \mathrm{~m}^{3} / \text { hari }
$$

Durasi $=$ Volume $/$ Kapasitas Produksi

$$
\begin{aligned}
& =5.449,54 \mathrm{~m}^{3} / 17,14 \mathrm{~m}^{3} / \mathrm{jam} \\
& =317,94 \mathrm{jam} \\
& =45,42 \text { hari }
\end{aligned}
$$

Durasi pekerjaan untuk galian biasa berdasarkan perencanaan $=21$ hari

Sehingga diperoleh jumlah kebutuhan dump truck pada pekerjaan galian biasa adalah sebagai berikut:

$$
\begin{aligned}
\text { Kebutuhan alat } & =\frac{\text { Volume pekerjaan }}{\text { Kapasitas produksi } x \text { Durasi }} \\
& =\frac{5449,54 \mathrm{~m} 3}{119,98 \mathrm{~m} 3 / \text { hari } \times 21,00 \text { hari }} \\
& =2,16 \approx 3 \text { unit }
\end{aligned}
$$

Perhitungan kebutuhan alat berat untuk tahapan pekerjaan lainnya disajikan dalam bentuk tabel.

$\begin{array}{lr}\text { Fakultas Teknik UMSB } & \text { ISSN 2599-2081 } \\ \text { EISSN 2599-2090 }\end{array}$


Tabel 2. Rekapitulasi Produktivitas Alat Berat

\begin{tabular}{|c|c|c|c|c|}
\hline No. & $\begin{array}{c}\text { Uraian } \\
\text { Pekerjaan }\end{array}$ & Sat. & $\begin{array}{l}\text { Kapasitas } \\
\text { Produksi }\end{array}$ & $\begin{array}{c}\text { Time } \\
\text { Factor }\end{array}$ \\
\hline \multirow[t]{2}{*}{1.} & \multicolumn{4}{|c|}{ Galian Biasa } \\
\hline & $\begin{array}{l}\text { Excavator } \\
\text { Dump } \\
\text { Truck }\end{array}$ & $\begin{array}{l}\mathrm{m}^{3} \\
\mathrm{~m}^{3}\end{array}$ & $\begin{array}{l}41,17 \\
17,14\end{array}$ & $\begin{array}{l}0,90 \\
2,16\end{array}$ \\
\hline \multirow[t]{2}{*}{2.} & \multicolumn{4}{|c|}{ Timbunan Biasa } \\
\hline & $\begin{array}{l}\text { Excavator } \\
\text { Dump } \\
\text { Truck } \\
\text { Motor } \\
\text { Grader } \\
\text { Vibrator } \\
\text { Roller }\end{array}$ & $\begin{array}{l}\mathrm{m}^{3} \\
\mathrm{~m}^{3} \\
\mathrm{~m}^{3} \\
\mathrm{~m}^{3}\end{array}$ & $\begin{array}{r}29,65 \\
4,29\end{array}$ & $\begin{array}{l}0,08 \\
0,56\end{array}$ \\
\hline \multirow[t]{2}{*}{3.} & \multicolumn{4}{|c|}{ Timbunan Pilihan } \\
\hline & $\begin{array}{l}\text { Wheel } \\
\text { Loader } \\
\text { Dump } \\
\text { Truck } \\
\text { Motor } \\
\text { Grader } \\
\text { Tandem } \\
\text { Roller } \\
\text { Water Tank } \\
\text { Truck }\end{array}$ & $\begin{array}{l}\mathrm{m}^{3} \\
\mathrm{~m}^{3} \\
\mathrm{~m}^{3} \\
\mathrm{~m}^{3} \\
\mathrm{~m}^{3}\end{array}$ & $\begin{array}{l}49,05 \\
26,00\end{array}$ & $\begin{array}{l}0,48 \\
1,60 \\
0,14 \\
0,26 \\
0,15\end{array}$ \\
\hline 4. & \multicolumn{4}{|c|}{ Penyiapan Badan Jalan } \\
\hline
\end{tabular}

Lanjutan Tabel 2.Rekapitulasi Produktivitas

\begin{tabular}{|c|c|c|c|c|}
\hline \multicolumn{5}{|c|}{ Alat Berat } \\
\hline No. & $\begin{array}{c}\text { Uraian } \\
\text { Pekerjaan }\end{array}$ & Sat. & $\begin{array}{c}\text { Kapasitas } \\
\text { Produksi }\end{array}$ & $\begin{array}{l}\text { Time } \\
\text { Factor }\end{array}$ \\
\hline & $\begin{array}{l}\text { Motor } \\
\text { Grader }\end{array}$ & $\mathrm{m}^{3}$ & 185,25 & 0,31 \\
\hline & $\begin{array}{l}\text { Vibrator } \\
\text { Roller }\end{array}$ & $\mathrm{m}^{3}$ & 39,00 & 1,47 \\
\hline & $\begin{array}{l}\text { Water Tank } \\
\text { Truck }\end{array}$ & $\mathrm{m}^{3}$ & 46,88 & 1,22 \\
\hline 5. & \multicolumn{4}{|c|}{ Lapis Pondasi Agregat Kelas A } \\
\hline & $\begin{array}{l}\text { Wheel } \\
\text { Loader }\end{array}$ & $\mathrm{m}^{3}$ & 65,61 & 0,19 \\
\hline & $\begin{array}{l}\text { Dump } \\
\text { Truck }\end{array}$ & $\mathrm{m}^{3}$ & 6,85 & 1,77 \\
\hline
\end{tabular}

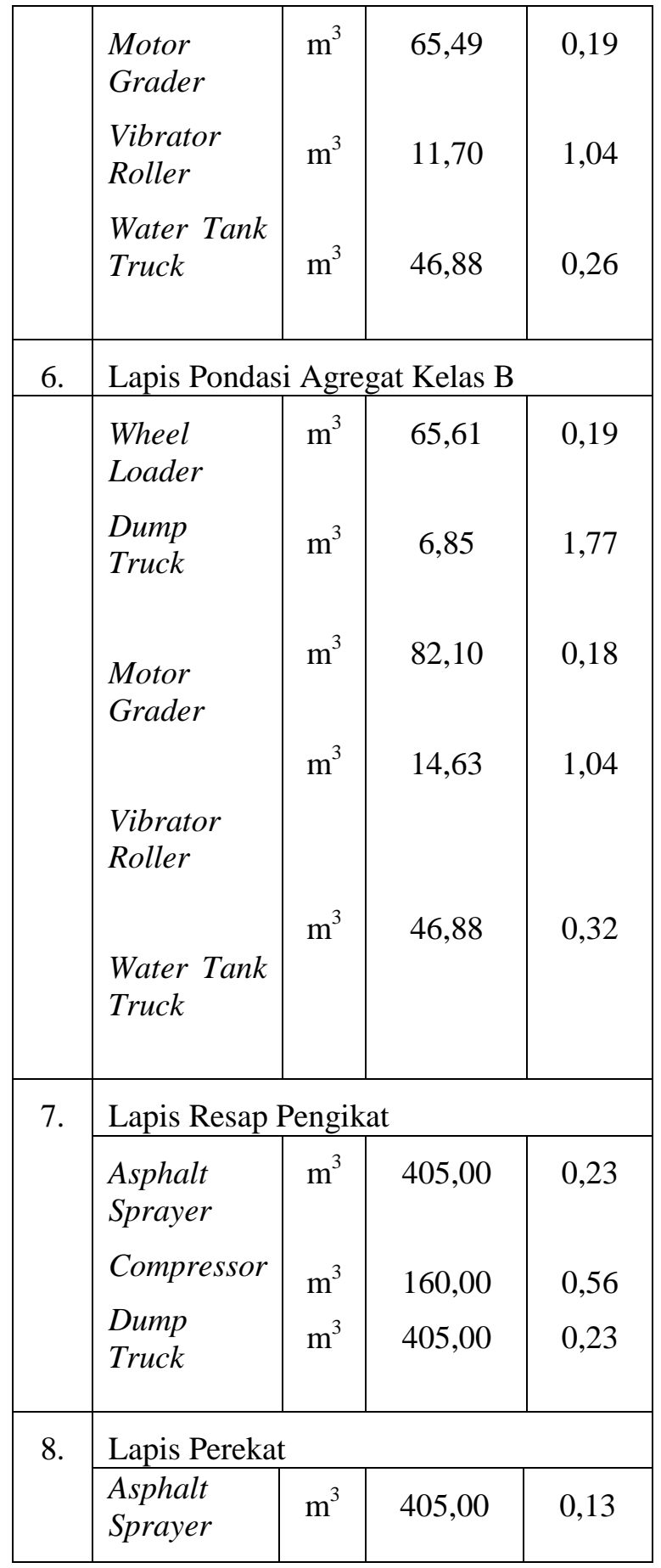

Lanjutan Tabel 2.Rekapitulasi Produktivitas Alat Berat

\begin{tabular}{|c|l|c|c|c|}
\hline No. & $\begin{array}{c}\text { Uraian } \\
\text { Pekerjaan }\end{array}$ & Sat. & $\begin{array}{c}\text { Kapasitas } \\
\text { Produksi }\end{array}$ & $\begin{array}{c}\text { Time } \\
\text { Factor }\end{array}$ \\
\hline & Compressor & $\mathrm{m}^{3}$ & 160,00 & 0,91 \\
& Dump & $\mathrm{m}^{3}$ & 405,00 & 0,13 \\
& Truck & & & \\
\hline 9. & \multicolumn{4}{|l}{ Asphalt Concrete } \\
\hline
\end{tabular}


Vol. 2 No.1 Januari 2019

http://jurnal.umsb.ac.id/index.php/RANGTEKNIKJOURNAL

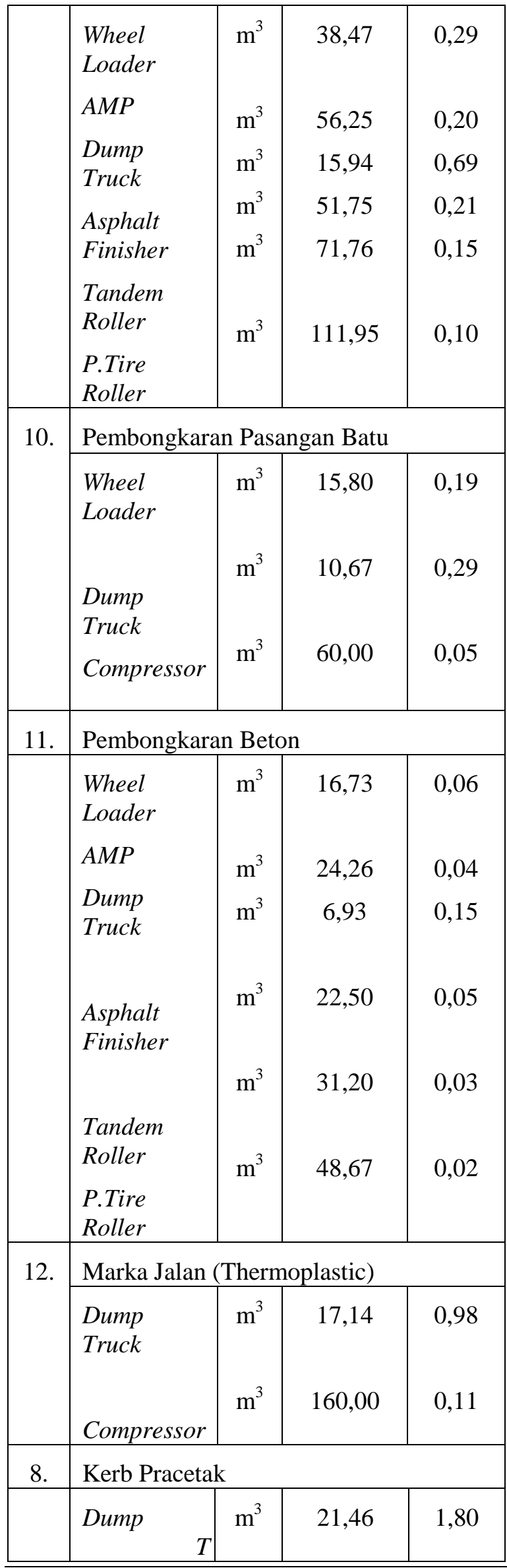

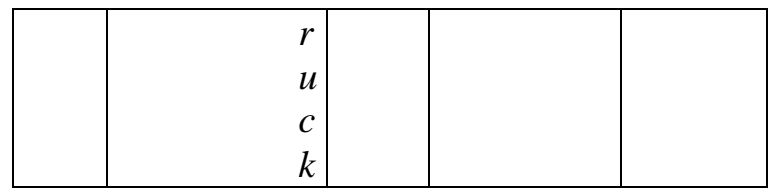

Analisa Penjadwalan dengan Metode Line of Balance

Pada proyek ini pelaksanaan pekerjaan dilakukan hanya berdasar pada schedule Kurva'S', agar lebih mendetail analisa dilakukan menggunakan metode penjadwalan linear (line of balance) dengan memplot durasi perencanaan yang ada di analisa perhitungan jumlah alat berat terhadap stasiun kerja dilapangan sehingga diperoleh diagram vektor untuk setiap jenis pekerjaan seperti dibawah ini.

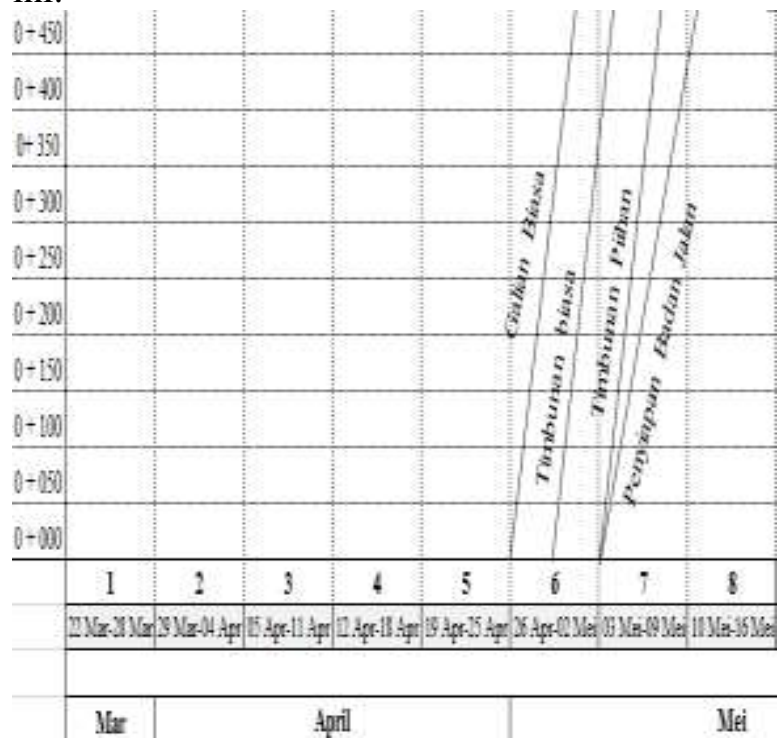

Gambar 1. Diagram Vektor LOB

Dari hasil analisa perhitungan, perencanaan alokasi kebutuhan alat berat dan penjadwalan di atas diperoleh total kebutuhan alat berat yang efektif yang dibutuhkan di lapangan, sebagai berikut :

Tabel 4.3. Total Kebutuhan Alat Berat 


\begin{tabular}{|c|c|c|}
\hline No. & Jenis Alat Berat & Total Kebutuhan Unit \\
\hline \hline 1 & Excavator & 1 \\
2 & Dump Truck & 7 \\
3 & Wheel Loader & 1 \\
4 & Motor Grader & 1 \\
5 & Tandem Roller & 1 \\
6 & Vibrator Roller & 2 \\
7 & Water Tanker Truck & 2 \\
8 & Asphalt Sprayer & 1 \\
9 & Compressor & 1 \\
10 & Asphalt Finisher & 1 \\
11 & Pneumatic Tire Roller & 1 \\
\hline
\end{tabular}

Berdasarkan tabel diatas diperoleh jumlah alat berat yang digunakan. Untuk Dump Truck diperoleh 7 unit sedangkan jumlah pada perencanaan awal sebanyak 10 unit, Wheel Loader 2 unit sedangkan pada perencanaan awal 1 unit, Excavator diperoleh 1 unit sedangkan jumlah pada perencanaan 2 unit, Water tanker diperoleh 2 unit sedangkan pada perencanaan 1 unit. Untuk alat berat lainnya diperoleh jumlah yang sama dengan perencanaan awal yaitu Wheel loader 1 unit, Motor Grader 1 unit, Vibrator Roller 2 unit Tandem Roller 1 unit, Pneumatic Tire Roller 1 unit, Asphalt Mixing Plant 1 unit, Asphalt Finisher 1 unit, Aspal Sprayer 1 unit dan Compressor 1 unit.

\section{SIMPULAN}

Dari hasil pengamatan dan analisa data maka dapat disimpulkan bahwa :

1. Produktivitas peralatan dipengaruhi oleh kapasitas produksi alat berat pada setiap jenis pekerjaan. Semakin besar kapasitas produksi suatu alat maka koefisien alat semakin kecil sehingga biaya yang dikeluarkan semakin kecil pula. Hal ini disebabkan karena peralatan yang digunakan pada setiap jenis pekerjaan bekerja secara efektif.

2. Jumlah kebutuhan alat berat diplot ke dalam vektor Line of Balance sehingga dapat diketahui posisi penempatan alat berdasarkan waktu pelaksanaan, jadi penggunaan alat dapat dikontrol agar lebih efektif.

3. Beberapa pekerjaan memiliki time factor peralatan yang kecil, dikarenakan durasi kerja yang panjang dan faktor lokasi proyek yang berada dalam salah satu daerah yang memiliki kepadatan kendaraan yang cukup tinggi

4. Durasi hari kerja bisa dipercepat dengan meningkatkan produktivitas sumber daya peralatan dan tenaga kerja.

\section{SARAN}

1. Tersedianya perencanaan alokasi kebutuhan alat berat sangatlah penting dalam suatu proyek sehingga tidak menimbulkan pemborosan tenaga kerja, modal, produktivitas serta memenuhi kebutuhan keselamatan.

2. Penjadwalan dengan menggunaan metode Line of Balance akan lebih efektif jika data yang tersedia untuk membuat penjadwalan lebih mendetail. Selain itu dapat pula lebih memudahkan dalam monitoring pelaksanaan pekerjaan.

3. Produktivitas pekerjaan dalam suatu proyek sangat dipengaruhi oleh umur ekonomis peralatan. Oleh karena itu, disarankan agar jika umur alat berat yang digunakan pada suatu jenis pekerjaan telah melebihi umur ekonomis maka sebaiknya alat berat tersebut tidak digunakan lagi agar waktu dan hasil pekerjaan dapat terkontrol dengan baik sehingga mengurangi faktor-faktor biaya yang tidak perlu.

\section{DAFTAR PUSTAKA}

Anonim. 2012. Cara Membuat Barchart Proyek. http://www.ilmusipil.com/caramembuat-bar-chart-proyek.html. Diakses tanggal 15 Desember 2012.

Asiyanto, Ir, MBA, IPM. 2008. Manajemen Alat Berat Untuk Konstruksi, Penerbit PT. Pradnya Paramita. Jakarta.

Gani, Muchtar, Ir, Msi. Bahan Kuliah PTM/Alat Berat. Jurusan Sipil Fakultas Teknik Universitas Hasanuddin. Makassar.

Http://www.google earth.com.html. Di akses tanggal 16 Januari 2013.

Iskandar. 2008. Metoda Schedule Linear (Line of

Balance)

http://iskandarmt.wordpress.com/2008/02/2

8/metoda-schedule-linear-line-of-

balance.html. Diakses tanggal 17 Desember 2012.

Rochmanhadi, Ir, M.Sc. 1992. Alat-Alat Berat dan Penggunaannya. Yayasan Badan Penerbit Pekerjaan Umum. Jakarta. 
Priana, Ir Surya Eka. "Pengaruh Kualifikasi Kontraktor Terhadap Kualitas Pekerjaan Proyek Konstruksi Di Kabupaten Tanah Datar." RANG TEKNIK JOURNAL 1.2 (2018).

Priana, Surya Eka. "ANALISA FAKTOR PENYEBAB KERUSAKAN JALAN (STUDI KASUS RUAS JALAN LINGKAR UTARA KOTA PADANG PANJANG)." Rang Teknik Journal 1.1 (2018).

Sosrodarsono, Suyono, Ir. 1985. Perhitungan Biaya Pelaksanaan Pekerjaan Dengan Menggunakan Alat-Alat Berat. Yayasan Badan Penerbit Pekerjaan Umum. Jakarta.

Saodang, Hamirhan, Ir, MSCE. 2009. Edisi 3 Struktur dan Konstruksi Jalan Raya. Penerbit Nova. Bandung.

Mangunsewang \& Karmila. 2011. Penjadwalan Dan Alokasi Alat Berat Pada Proyek Peningkatan Jalan Poros BantaengBulukumba. Makassar : Skripsi Teknik Sipil Universitas Hasanuddin.

Yaghootkar, Kazem. 2010. Line of Balance (LOB). http://project-managementreview.blogspot.com/2007/09/line-ofbalancelob.html. Di akses tanggal 17 Desember 2012. 